\section{Gategory}

Synthesis of

Materials and

Unnatural Products

\section{Key words}

graphene nanoribbons

cyclodehydrogenation

\section{Diels-Alder} reaction

\section{near-infrared} absorption

X. FENG, ${ }^{*}$ K. MÜLLEN* ET AL. (MAX PLANCK INSTITUTE FOR POLYMER RESEARCH, MAINZ AND FREE UNIVERSITY BERLIN, GERMANY; UNIVERSITY OF LEUVEN, BELGIUM; FOM INSTITUTE AMOLF, AMSTERDAM, THE NETHERLANDS; AARHUS UNIVERSITY, DENMARK; MANCHESTER UNIVERSITY, UK)

Bottom-Up Synthesis of Liquid-Phase-Processable Graphene Nanoribbons with Near-Infrared Absorption ACS Nano 2014, 8, 11622-11630.

\title{
A Diels-Alder Approach to Graphene Nanoribbon Precursors
}

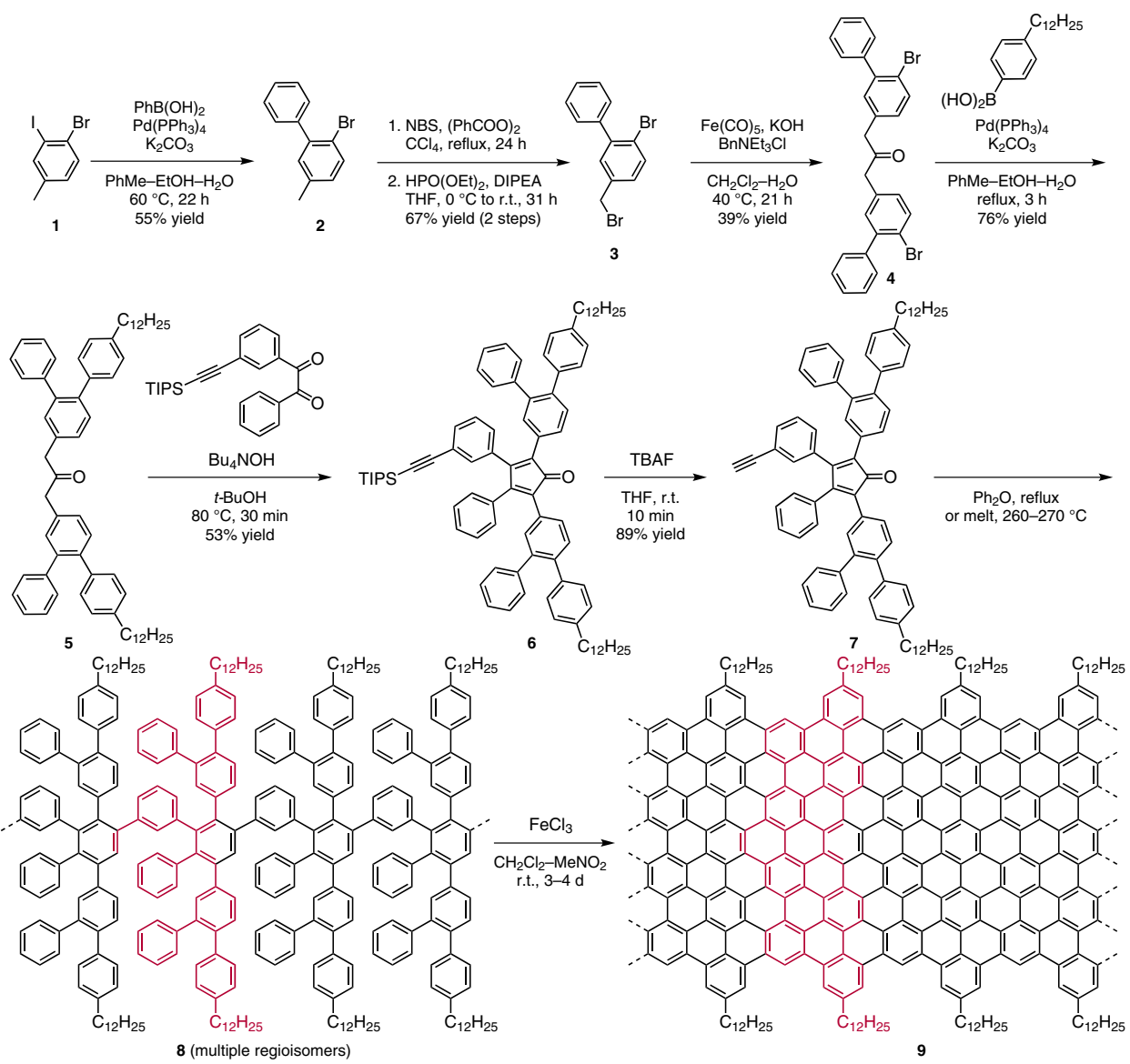

Significance: Bottom-up approaches to graphene nanoribbons (GNRs) have been limited by the short length of nanoribbons produced $(<50$ $\mathrm{nm}$ ) or the requirement for metal surfaces. The authors report a bottom-up approach to the synthesis of longer (>100 nm), structurally defined GNRs using an $A B$-type Diels-Alder polymerization to form nanoribbon precursors 8 that can be planarized to GNRs 9 by oxidative cyclodehydrogenation with $\mathrm{FeCl}_{3}$

SYNFACTS Contributors: Timothy M. Swager, Kathleen R. White Synfacts 2015, 11(1), 0036 Published online: 15.12.2014 DOI: 10.1055/s-0034-1379666; Reg-No.: S12514SF 